\title{
Monitoring Mechanism in Preservation of Monuments in Hot and Wet Climate Area
}

(Bureau of Cultural Heritage, Ministry of Culture, Taichung, Taiwan, Republic of China -Part of the Results of the Study)

$$
\text { M.C. Lee }{ }^{\text {a, } *, Y . L . ~ T s a i ~}{ }^{\text {b }} \text {,M.L. Lin }{ }^{\text {a }} \text {, L.W. Hang }{ }^{\text {a }} \text {, C.Y. Chen }{ }^{\text {a }}
$$

Dept.of Interior Design, National Taichung University of Science and Technology, 40401, Taichung Taiwan-MCJL@nutc.edu.tw

${ }^{b}$ Bureau of Cultural Heritage, Ministry of Culture, 402, Taichung,Taiwan-ch0215@boch.gov.tw

\section{Commission VI, WG VI/4}

KEY WORDS: Preservation monitoring, impact factors of environment, preservation objects, preservation methodology, preservation periods

\begin{abstract}
:
Historic monuments and buildings are critical cultural assets which cannot be presented by again by human beings. Longer affected by natural climate, environment and biological behavior (including human), resulting in damage and the need for repair. Therefore, UNESCO proposed periodic reporting and reactive monitoring in 2007, in order to achieve "early detection, early repair".

This study discusses about suitable preservation monitoring methods for Taiwan. To shed light on damage and impact factors of historical buildings and cultural relics, the study is based on impact and sensor, monitoring method, monitoring period and maintenance personnel in order to propose standard operating procedures of monitoring method.

To reduce the rate of the human and sensor monitoring, with the long-term monitoring data analysis, it is calculated that 30 minutes is the best period of data collecting. Besides, the study is adopted regression analysis to select temperature variable only then calculate humidity variable function.

This study provides a reference monitoring method for monitoring personnel and maintenance personnel, and establishes a long-term monitoring data based information for damage and destroy in the future. Monitoring period and maintenance personnel can follow the data based to find out the damage points and problems, to keep the value of cultural assets.
\end{abstract}

\section{INTRODUCTION}

\subsection{General Background Information}

Monitoring is a method to prevent cultural heritage from damage. In the past, UN, Japan and China did the relative researches to investigate the effect of climate on cultural heritage and to analyse its risk, and proposed that preventative monitoring is more valuable than reconstructing after climate damage. According to UNESCO “The Operational Guidelines for the Implementation of the World Heritage Convention (2005), it simplified the old 31 monitoring processes into 11 priority processes ( 171 EX/Decision 27, Paragraph 5 ) to monitor for such buildings, and proposed solutions in 2007 ( 34 C/Resolution 87) to achieve the goal "early detection, early repair."

Taiwan is an island located in the Tropic of Cancer and with undulating terrain. The climate here changes greatly; summer is hot and wet, but winter is cold and dry. Taiwan also locates between in the Eurasian Plate and the Philippine Plate; therefore, earthquakes occur frequently and also cause windstorm and flood which become the major natural disasters of Taiwan.

Taiwan was colonized by Dutch, Spanish, Kingdom of Tungning, Qing Dynasty and Japanese. In these colonials period, different materials and construction methods were made Taiwan's heritages has different style. Because colonial buildings style were adapted to climate, made this island with different damage conditions occurs on the different colonial heritages. Cultural heritages in Taiwan are long-term damaged by natural climate, surrounding environments, natural disasters and improper artificial. The damages even reduce cultural heritages value. The technique, material and many problem conditions cannot reconstruct very well even spend a lot of money. In recent years, Taiwan is pushing monitoring system and standardization, based on UNESCO "Convention Concerning the Protection of the World Cultural and Natural Heritage" and it's "Operations Guide" for warning and management measures of feedback correction.

\subsection{Scope of the study}

For cultural heritage preservation, damage factors are divided into natural aging, environmental degradation and natural disasters, vandalism, etc. Natural disasters and vandalism belong to disaster relief, therefore, this study focus on natural aging and environmental monitoring as shown in Figure1.

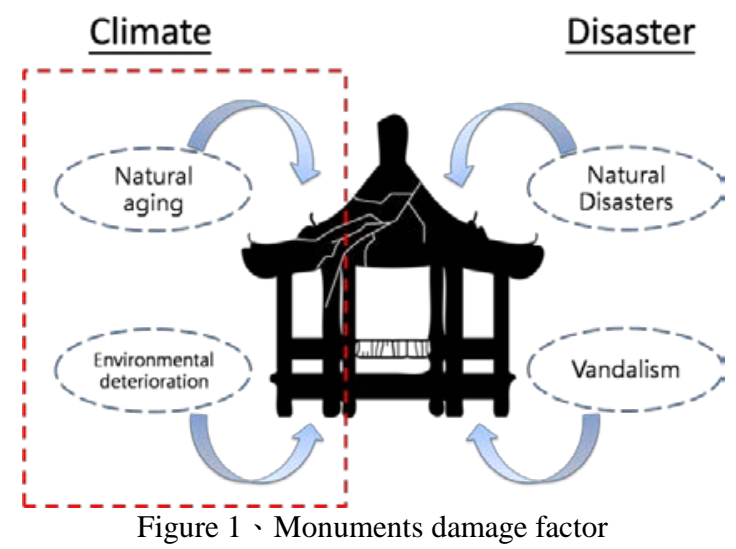


Building types and materials are consider on local characteristic. Therefore, preservation monitoring is according to heritage damage types to set up monitoring method. Combine with monitoring method, sensor and damage range to be a monitoring management system.

Because Taiwan's location, construction type, man-made damages and natural disasters are different to other countries, this prevention monitoring method is suitable for Taiwanese heritage.

Monitoring the factors of damage for cultural heritage is a way to protect the value of cultural heritage, to keep history.

\section{LITERATURE REVIEW}

\subsection{Monitoring priorities in Foreign}

Prevention monitoring reference to UNESCO “The Operational Guidelines for the Implementation of the World Heritage Convention" monitoring mechanism, by performing this monitoring mechanism of periodic reporting and reactive monitoring propose to monitor the long-term variation of natural disasters and being monitoring after damage or deterioration, then grasp the phenomenon of damages and proposing preservation and maintenance immediately. EU countries were already executed preventive monitoring, and the development of a European monitoring methods applied, such as: FP5-FP6 “Noah's Ark EU”. Noah's Ark plan is to draw EU climate risk maps of temperature and humidity to grasp the risks of the location of heritage; then execute FP7 "Climate for Culture" plan to study the effects of climate on cultural heritage and long-term monitoring and analysis of the risks in the project plan. Basic monitoring are temperature, relative humidity and HVAC (Heating, Ventilation and Air Conditioning) ventilation rate.

\subsection{Monitoring priorities in Taiwan}

By literatures review and field survey, culture heritages were effect by three different environmental damages; (1)mechanical, (2)chemical, (3)biological. Common mechanical damage; peeling, cracking, deformation, bending, rising moisture, aging, stagnant air, dust deposition, etc. due to thermal expansion and contraction, moisture expansion and drying shrinkage and UV (Ultraviolet) irradiation etc. Common chemical damage is following; mold, organic compounds, metamorphism, carbonation, weathered, etc. Mainly caused by chemical contaminants; common biological damage: pest, mold, fungi, plants attached climbing, often causing damage to building materials. The main influencing factors for the damage were temperature, relative humidity and moisture. These three environmental factors are basic monitoring objects. Secondly, advanced monitoring projects for other factors, such as wind and light, as shown in Figure 2.

This study is investigated people, things, times, places, objects for preservation monitoring in Taiwan. (1) Climate risk (places) By climate data analysis and geographic information system database, according to materials (wood, masonry, metal) made of laminated map of cultural heritage. The establishment of exclusive material and cultural heritage climate risk maps, and made with the possible impact of the different risk levels of the distribution position, as shown in Figure 3.( Wu, Ping-Sheng, 2012)(2) Monitoring objects (objects): for culture heritage, building (outdoor), building (indoor),

Specific attachments (unmovable) and furnishings (removable), as shown in Figure 4. (3) Monitoring methods (things): summarized the common factor in wood, masonry and reinforced concrete (temperature, humidity and moisture content) and adopt monitoring sensors and select the appropriate monitoring places. (4) Monitoring period (time): long-term monitoring is recommended 30 minutes a data monitoring mechanisms remaining cases vary slightly due to adjustments. (5) Maintenance staff (person): Maintenance staff can be divided into monitoring staff and maintenance staff. Finally, prevention monitoring place basis as a reference place is the subject of a map according to Taiwan's cultural asset risk classification, highest risk and high risk areas susceptible to environmental factors affect the material damage, start monitoring with highest risk and high risk areas. Secondly consider the type of construction and the material properties of cultural heritage, such as wooden structure, masonry structure with reinforced concrete structure, as well as consideration of cultural heritage themselves cultural, historical and artistic value is extremely important, and is located in geographic considerations are final.

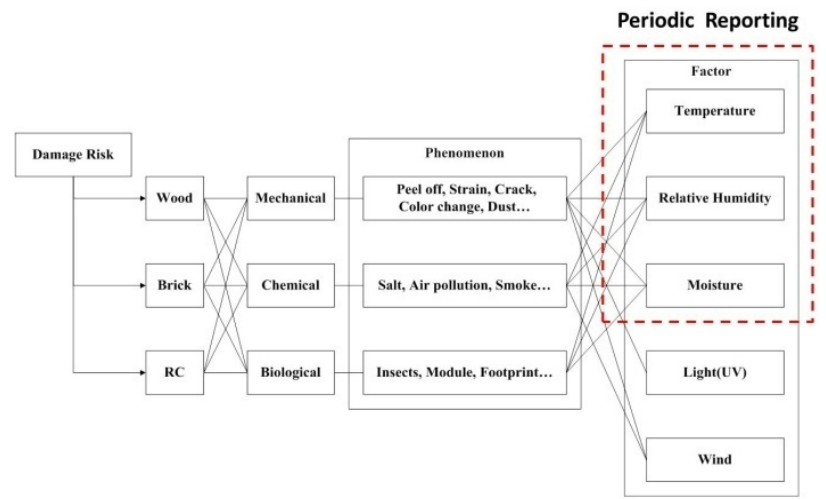

Figure 2、 Periodic Reporting of factors

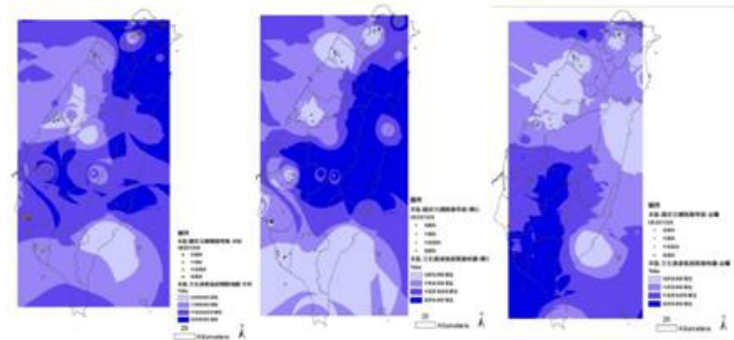

Figure 3、Taiwan Heritage Risk Maps(Wu, Ping-Sheng , 2012)

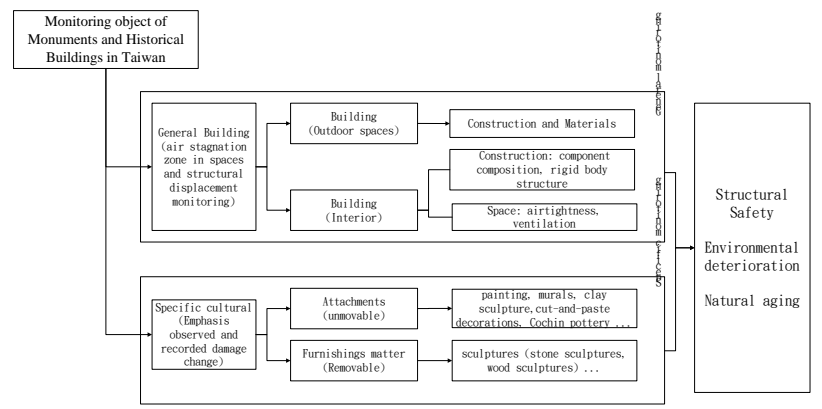

Figure 4 - Monitoring object illustrating of monuments and historical buildings in Taiwan

\section{ESTABLISHMENT OF MONITORING MECHANISM}

There are three monitoring mechanism in this study, field survey, periodic reporting, reactive monitoring. Field survey is to understand the heritage environmental conditions, to find out 
stagnant air and damage places to facilitate the subsequent longterm monitoring operations. Periodic reporting to monitor cycle (time point) was discussed, including daily monitoring and periodic monitoring. Daily monitoring means will produce change at any time and cause a significant impact on long-term accumulation. Damage situation in a short period of time cycle, about once a month to monitor the quarter; periodic monitoring of the situation in a period of damage long-period changes in about six months or once a year to monitor means a period of time before any significant changes, including periodic monitoring and creep change monitoring. Reactive monitoring is monitoring serious damages (found repeated mechanical or biological changes lead to serious damages) and after disaster monitoring (immediately monitoring after serious damage). Monitoring mechanisms for environmental or structural monitoring sampling period and then distinguish and describe monitoring factors and inferiority damage factors, as shown in Figure 5.

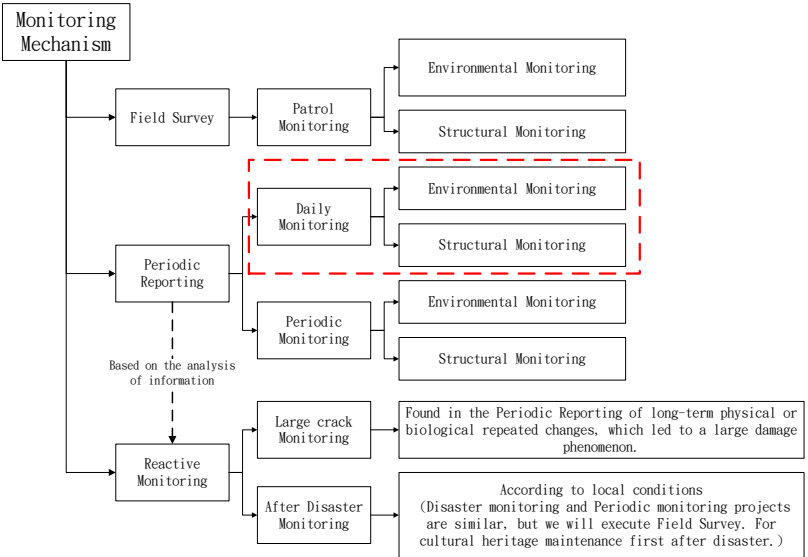

Figure 5 - Monitoring mechanism of monuments and historic buildings preservation monitoring system

\section{VERIFICATION -DAILYENVIRONMENTAL MONITORING}

Use Taiwan heritage risk maps characteristic for highest risk area select, as shown Figure 6. This study was according Taiwan heritage risk map to select highest area to monitoring. Secondly consider the type of construction and the material properties of cultural heritage as wood construction, masonry construction and reinforced concrete structures, as well as cultural and historical value heritage themselves. The finally considerations is location. This study is select Beigang-ChaoTian Temple, as shown in Table 1.

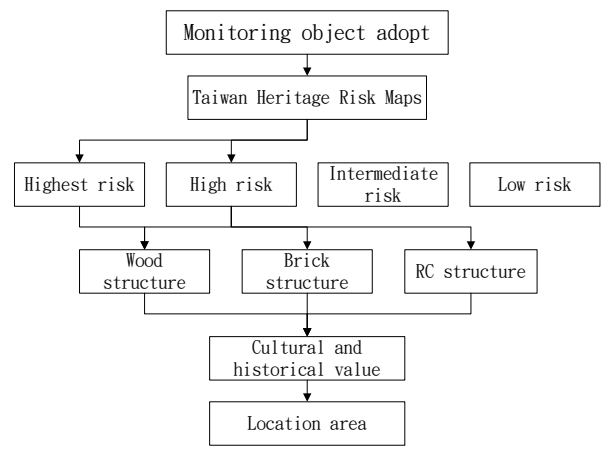

Figure 6、Monitoring object adopt

\begin{tabular}{c|c|c|c|c|c|}
\hline $\begin{array}{c}\text { Monuments } \\
\text { Category }\end{array}$ & Risk Level & Materials & Historical value & $\begin{array}{c}\text { Administrative } \\
\text { region }\end{array}$ & Building \\
\hline $\begin{array}{c}\text { Country } \\
\begin{array}{c}\text { Cultural assets } \\
\text { Temple }\end{array}\end{array}$ & $\begin{array}{c}\text { Wood : Highest risk } \\
\text { Brick: High risk } \\
\text { Metal : High risk }\end{array}$ & $\begin{array}{c}\text { RC } \\
\text { Wood }\end{array}$ & $\begin{array}{c}\text { Historical, cultural } \\
\text { and artistic value }\end{array}$ & $\begin{array}{c}\text { Beigang Township, } \\
\text { Yunlin County }\end{array}$ & $\begin{array}{c}\text { Beigang } \\
\text { Chao-Tian Temple }\end{array}$ \\
\hline
\end{tabular}

Table 1 - Monitoring object adopt for Beigang Chao-Tian Temple

After about a year of periodic reporting monitoring and analysis the monitoring data and present the results of periodic reporting of Beigang-Chao-Tian Temple. Before periodic reporting to carry out monitoring of current exploration, find damage places, stagnant air area and large variation places to setting the monitoring equipment. This study selected three the same column prayer places in Beigang Chao-Tian Temple: San Guan Dian, Guan Yin Dian and Wen Chang Dian as a periodic reporting object. Sensors located in the space of about four corners of the height about $360 \mathrm{~cm}$ (high position) and $60 \mathrm{~cm}$ (low position), as shown in Figure 7 and Figure 8. Height and position of the measuring point selection, because $360 \mathrm{~cm}$ (high position) part of the steady flow at the height put this is to avoid external airflow impact monitoring results, and the hot air will rise to the top then find out the location of the four large variation places or stagnant air area. $60 \mathrm{~cm}$ (low position) put in the middle of the space, in order to avoid rising moisture, as shown in Figure 9.

$\ulcorner$ Effective monitoring $\lrcorner$ (high risk by the physical destruction from large variation location) can reduce human resources and equipment. $\ulcorner$ Effective variation $\lrcorner$ verified severely damaged by mechanical, so this section is worth further study the relationship between material by physical damage and environmental factors. Sensors put on the two large variations location after monitoring data analysis. The temperature ofhigh positions is higher than in the temperature of low positions, and the relative humidityof high positions is lower than the relative humidity of low positions.

Difference in temperature about $3{ }^{\circ} \mathrm{C} \sim 4^{\circ} \mathrm{C}$ on the high positions and low positions in summer, difference in relative humidity difference about 10 to $15 \%$ in summer, as shown in Figure 10. When air expands increases moisture of unit volume, causing relative humidity drops. The temperature is higher the relative humidity is lower, but the temperature is lower the relative humidity is higher. Monuments affected by thermal expansion and shrinkage of swelling of the physical changes in long-time, affect stability of the structure. Prevention monitoring purposes can reduce sensor in the future.

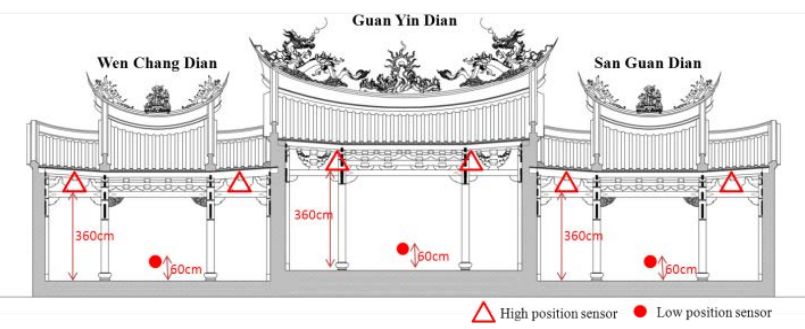

Figure7 、 Sensors of height position in Beigang Chao-Tian Temple 


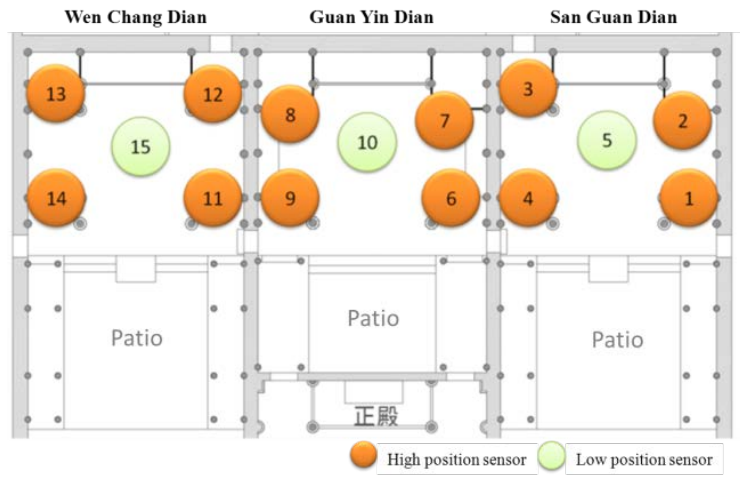

Figure 8 - High position sensor of position in Beigang ChaoTian Temple

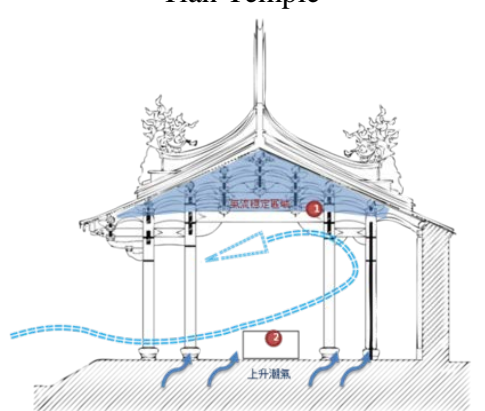

Figure 9 - Airflow distribution map in Beigang Chao-Tian Temple

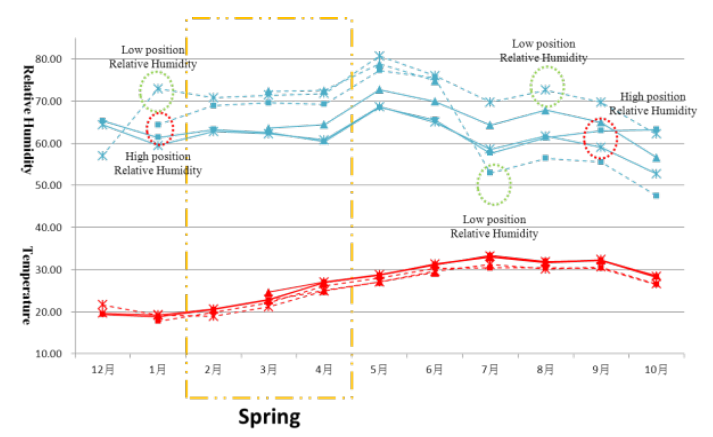

Figure10 - Temperature and relative humidity run chart of high and low position in Beigang Chao-Tian Temple

\section{DISCUSSION}

Predicted linear regression equations can find difference in relative humidity by difference in temperature in each prayer place high position and low position in the middle of the room. This case predicted linear regression equations of four seasons of San Guan Dian, as shown in Figure 11.Regression analysis can be seen in R2 values are greater than 0.9 , which means that the launch of the equation with high accuracy. Four seasons to get the equation for $\Delta \mathrm{RH}=\alpha(\Delta \mathrm{T})+\beta . \alpha$ and $\beta$ are difference in seasons and interior spaces, as shown in Table 2 .

One high position sensor and one low position sensor put in the interior space in the future. Difference in temperature can calculate difference in relative humidity and assessment of abnormal values. So this study can reduce human resources and equipment in the future. $\mathrm{R}^{2}$ doesn't more than 0.95values in Table 2, so the values will be corrected by daily monitoring.

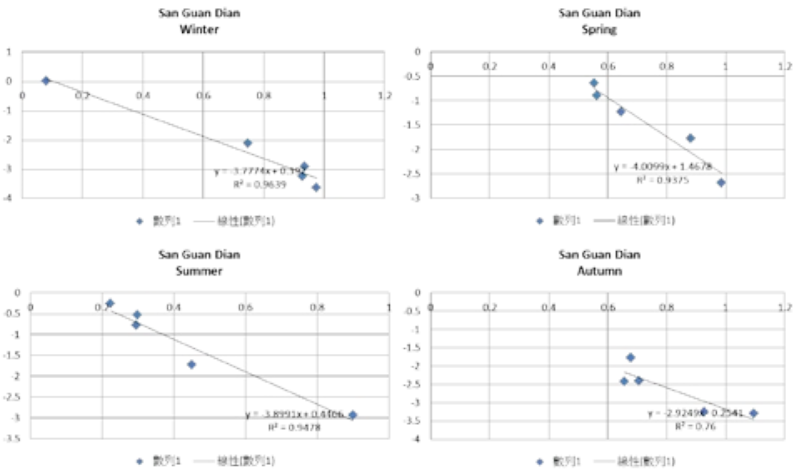

Figure11 - The function of seasons of San Guan Dian

\begin{tabular}{|c|c|c|c|c|c|c|c|c|c|c|c|c|}
\hline & \multicolumn{3}{|c|}{ Winter } & \multicolumn{3}{|c|}{ Spring } & \multicolumn{3}{|c|}{ Summer } & \multicolumn{3}{|c|}{ Autumn } \\
\hline & $\alpha$ & $\beta$ & $\mathrm{R}^{2}$ & $\alpha$ & $\beta$ & $\mathrm{R}^{2}$ & $\alpha$ & $\beta$ & $\mathrm{R}^{2}$ & $\alpha$ & $\beta$ & $R^{2}$ \\
\hline $\begin{array}{l}\text { SAN- } \\
\text { GUN- } \\
\text { DIAN }\end{array}$ & -3.78 & 0.39 & 0.96 & -4.01 & 1.47 & 0.94 & -3.90 & 0.45 & 0.95 & $-2,92$ & -0.25 & 0.76 \\
\hline $\begin{array}{l}\text { GUAN- } \\
\text { YINA } \\
\text { DIAN }\end{array}$ & -2.17 & -1.10 & 0.32 & -2.53 & 1.46 & 0.96 & -1.87 & -0.56 & 0.99 & -2.80 & $\mid-0.57$ & 0.76 \\
\hline $\begin{array}{l}\text { WAN- } \\
\text { CHANG- } \\
\text { DAAN }\end{array}$ & $\cdots$ & $\cdots$ & $\cdots$ & -3.57 & 0.59 & 0.99 & -3.64 & -0.24 & 0.99 & -2.85 & -0.45 & 0.88 \\
\hline
\end{tabular}

Table $2 、 \alpha \cdot \beta$ and $\mathrm{R}^{2}$ function of seasons of Beigang ChaoTian Temple

This study analysed data of daily environmental monitoring methods. Data correlation is high in a different position, so monitoring methods can do. And monitoring methods can put few sensors in the future, in order to achieve effective monitoring and master effective variation. Routine maintenance managers can refer to the use of this monitoring method in the future. Identify the location of variation values in new APP by the research teams.

This study proposes difference in temperature can find $\mathrm{E}$ value (Young's modulus) of the material, and difference in relative humidity can find EMC (Environmental Moisture Content) value. Other research projects, such as UV (Ultraviolet), wind, chemical, structural influence as monitoring projects can be studied in the future.

\section{ONCLUSION}

Monuments and historic buildings are Taiwan cultural assets, and cultural assets can't be reproduced. We have to preserve cultural assets, progeny can enjoy these cultural assets.

This study is discussing monitoring methods in preservation of monuments and historical buildings in Taiwan, in order to continue the preservation monuments and heritages. We choose Periodic Reporting validate monitoring methods, and we proposed monitoring methods for Taiwan. Data analysed by average, standard deviation and regression analysis from Periodic Reporting. Predicted linear regression equations can find difference in relative humidity by difference in temperature. This monitoring method can reduce human resources and equipment. Finally, this study proposed "effective monitoring" and "effective variation" are standard monitoring methods in preservation of monuments and heritages in Taiwan, establish basic information and transact special circumstances.

\section{ACKNOWLEDGEMENTS (OPTIONAL)}

Acknowledgements of support for the Monitoring methods in preservation of monuments and historical buildings project is Bureau of Cultural Heritage, Ministry of Culture, Taichung, Taiwan, Republic of China. 


\section{REFERENCES}

M.C. Lee, 2014. Monitoring Mechanism in Preservation of Monuments -Part of the Results of the Study, Bureau of Cultural Heritage

P.S. Wu, NCKU Research and Development Foundation, Taiwan's cultural heritage climate risk map build and research

C.M. Lin, etc., Antiquities preservation - Maintenance Manual, National Museum of History, Taipei

S.F. Yen, The Practice of Conservation at the National Palace Museum, Journal of Cultural Property Conservation, Vol.1(1),pp. 47-54

F.R. Juang, 1983. Monuments Management and Maintenance, Student Book Co., Ltd.

R.L. Yang, 2010. Why, How, and When Would Pests Get Into Museums or Archives?, Journal of Cultural Property Conservation, No.13, pp.79-88

F.J. Rong, C.C. Fu, 2009. The Influence and Inspiration of the "World Cultural Heritage" Monitoring Mechanism to Cultural Heritage Management Practices, Journal of Architecture, No.67, pp.57-80

Y.L. Tsai, M.C. Lee, 2014. Monitoring Mechanism in Preservation of Monuments in Taiwan

Y.S. Tsay, C.M. Chiang, 2009. Study on the Applicability of Moisture Buffering Materials in Taiwan, J Journal of Architecture No. 69, pp.35-50

Clarke, J. A., C. M. Johnstone, N. J. Kelly, R. C. McLean, J. A. Anderson, N. J. Rowan, and J. E. Smith, 1999. A technique for the prediction of the conditions leading to mould growth in buildings, Building and Environment, Vol. 34:515-512.

Dr. Johanna Leissner, 2008. Damage risk assessment, economic impact and mitigation strategies for sustainable preservation of cultural heritage in the times of climate change, FraunhoferGesellschaft

Damage risk assessment, 2011. Economic impact and mitigation strategies for sustainable preservation of cultural heritage in the times of climate change D 2.2, 7th Framework Programme, Environment

Ralf Kilian, Tomas Vyhlidal, Tor Broström, 2010. DEVELOPMENTS IN CLIMATE CONTROL OF HISTORIC BUILDINGS 